\title{
Enhanced e-Learning System for e-Courses Based on Cloud Computing
}

\author{
Ayman E. Khedr ${ }^{1}$, Amira M. Idrees ${ }^{2 *}$ \\ 1 Department of Information Systems, Faculty of Computers and Information, Helwan University, Cairo, \\ Egypt. \\ 2 Department of Information Systems, Faculty of Computers and Information, Fayoum University, Fayoum, \\ Egypt. \\ * Corresponding Author. Tel.: 02-01113900394; email: ami04@fayoum.edu.eg \\ Manuscript submitted October 29, 2015; accepted December 28, 2015. \\ doi: 10.17706/jcp.12.1.10-19
}

\begin{abstract}
The Egyptian higher education sector was being subjected to a number of changes due to the policies made by the government. To enhance the role of the private sector, the authorities have embarked on an ambitious and comprehensive financial plan of reform that is to be completed over a ten-year span for the target of making the higher education institutions more competitive and efficient. The reform strategy addresses three key issues, they are, strengthen the system through consolidation and privatization of smaller joint ventures and public education institutions. The second issue is restructuring higher education public sector institutions, including recapitalization. And finally the effective adoption of a new technology for enhancing educational process.

In this research, we focus on the adoption CC in universities to enhance educational process for higher education. The main aspects of educational process consist of academic staff, researcher, student, administrative, data and research in the field of e-course in learning process. Logical data should fulfill the satisfaction of student and researcher, which academic staff and administrative are responsible for that. The materials should be trusted from academic staff to serve student and researcher; all of these aspects enhance the effective process in higher education.
\end{abstract}

Key words: E-learning, cloud computing, saas, educational process, e-courses.

\section{Introduction}

E-learning has been realized as an efficient way of learning. However, the increasing number of students, services, education contents and resources as well as the way of adapting e-learning system have become problematic. Being challenged by the growing needs, educational institutions are facing problems in providing the necessary Information Technology support for educational research and development of activities. With the progress of technologies, the emergence of cloud computing offers a good opportunity to develop e-learning, so many arisen problems could be resolved [1]. Cloud computing mainly aimed at running applications as services over the internet on a scalable infrastructure [2]. Technologies of CC enable educational institutions that do not have the technical expertise to support their own infrastructure to get access to cloud computing on demand. Cloud computing makes it possible to deploy tools that can be scaled on demand to serve as many users as desired [1], [3], [4].

For many educational institutions, CC offers a cost-effective solution to the problem of how to provide 
services, data storage, and computing power to a growing number of internet users without investing capital in physical machines or special configuration, which need to be maintained and upgraded on-site [1].

Cloud services can be categorized into three main service models which are considered a layer in the cloud [5]-[7]. The first layer is the Infrastructure as a Service (IaaS). In this layer, the whole IT infrastructure can be delivered as a service. The second layer is the Platform as a Service (PaaS), a virtual platform over the internet gives users the ability to develop and deploy their applications. The third layer is the Software as a Service (SaaS). SaaS is the simplest layer of this category; it means accessing an application through the internet on demand. In the SaaS layer, the CSP provides a single instance on the cloud for multiple users. Google Apps, one of the most powerful SaaS that is used by many institutes to provide a variety of Web-based applications for business, education, and government [6]. In this research, we are providing an enhancement of the e-course in the educational process in the SaaS layer by providing the services of e-learning to the users as will be discussed in the remaining of the research.

The remaining of the research is structured as follows: Section 2 presents previous work in the same area, Section 3 discusses the research problem and Section 4 discusses the proposed methodology. The case study setup is presented in Section 5, while the proposed framework is presented in Section 6. Finally Section 7 demonstrates the results and the conclusion and future work are discussed in Section 8.

\section{Background and Related Works}

The educational process is based on a foundation of several different educational philosophies and approaches, it is important to identify the stages of the educational process for developing the learner skills. The educational philosophy process has defined education in [8] as "a synthesis of realist and idealist world views, with a primary focus on performance". Therefore, it is necessary to focus on the following issues [9]:

1) The process of education (defined as a performance-based philosophy of education): integrates many different educational theories, processes and technologies in emphasizing the continuous development of learning skills through the use of assessment principles to enhance the educational process.

2) In the age of strong competition among educational institutions, using advanced technologies and tools are considered as one of the most important transformational changes to enhance the educational process which also is required by higher education.

3) The advances in computing, multimedia, and communication technologies provide an opportunity to build a self-growing, unit sharing virtual environment for teaching and learning.

4) Education institutions that do not have the technical expertise attempt to implement CC to support their own infrastructure to get an easy access to cloud computing on demand.

5) Educational institutions need to tailor their services based on their students' individual requirements.

According to our research, different researches have introduced the benefits of using cloud systems in e-learning process [10], [11], other researchers such as [12], [13], have introduced the variables that are affected in the educational process including reliability and performance due to applying the cloud computing environment in the learning process. More researchers have presented an e-learning system based on cloud as in [14] which lacked the study regarding the attitude and strategy for migration to the proposed architecture based on clouds. Another research by [15] presented an e-learning environment based on cloud computing, however, the presented environment focused on using the existing web services to provide the required web applications with no intention to develop the suitable needed services in the learning process.

In developing countries, many researchers developed several investigations recently about the usability of e-learning in KSA such as in [16] which provided the advantage of using cloud systems in e- learning 
process to raise the process level including its efficiency, and reliability as well as the availability. Focusing on Egypt, different researches have also proposed the idea of applying cloud computing in the e-Learning process [15], [17]-[20], however, these researches have focused on using the proposed services provided by cloud, with no intension to apply new services which is more efficient to the learning process, moreover, the researchers neither presented a developed application for their proposed systems nor a practical study of the desired objective.

Focusing on more practical studies, Khedr et al. in [21] implemented a group of surveys which focused on the traditional e-course in the educational process. The surveys resulted in the exploration of the lack of effectiveness for teaching and learning for students, which in turn put a spot on the reason of the students' turning out of accessing e-courses. This result has revealed an evidence of the dissatisfaction of the students in using the traditional e-learning process.

Another research by Khedr et al. in [22] which presented a step forward towards an enhancement for applying traditional e- learning process by introducing the CC technology on the traditional process and proved a success in raising the students' satisfaction, however, the proposed work in this paper provided more enhancement by focusing on the e-course in the learning process.

\section{Research Problem}

Egyptian universities need to customize their services according to their students' individual needs based on accurate analysis and understanding of available historical data. Egyptian universities are faced with multiple problems most of which are related to the research issue on hand. They have to adopt CC to create knowledge from their large volume of available historical data and expertise that can support the decision makers in achieving their goals and to enhance the educational process. Accordingly, there is a need to appropriate adaptive framework that has a better inclusive insight into effects on the way of implementing $\mathrm{CC}$ on educational process in higher education emphasis on e-course learning based on cloud computing in Helwan University in Egypt as a research case.

\section{Proposed Methodology}

Using cloud computing for the adoption strategy includes four stages, with emphasis on the evaluation of data, processes, functions and applications from several major universities based on some criteria such as size and funds. In order to be applicable in practice, the proposed framework takes into account the university's architecture and criteria such as vision, mission, availability and importance of applications and also the data of mission, sensitivity, confidentiality, integrity and availability [23].

The following research activities and tasks have been carried out in order to provide meet the research objective:

1) Building a synthesis framework to preliminarily explore the effects of implementing cloud computing on enhancing e-course process in higher education, generally.

2) Evaluation of the conceptual framework in one large educational institution context (Egyptian environment). The Egyptian education sector is chosen as a higher education environment that generally displays different "opposing" factors in higher education institutions' environment.

3) Operationalize the conceptual framework to develop the appropriate framework. The framework should shed light on the ways of higher education that effect on the way of the implementation CC and its impact on the educational process.

4) Re-framing this framework into a new constructed working theory for further research in the field of implementing cloud computing in higher educational especially in the other fields of the educational process. 


\section{Case Study Set up}

The research in hand will take into consideration two of the system users (students, faculty) besides the institution's benefits (e.g., cost reduction). Recognizing the designing and devolving the e-course process; e-learning courses has been used in Egyptian universities by standard rules, instructions, structuring and design in the whole process for teaching and learning the necessary educational process in higher education; as depicted in Fig. 1.

The traditional way of e-learning is developed by the designer of the national center, the designer could design normally one style of the module in the course without any additional enhancement in the course process. The students start the lesson of the module, the lesson has five questions which should be answered by students before stating the teaching and learning process of e-course. The lesson has its ILOs that should be achieved after students finish the lesson. The lesson contains the power point, glossary, summary and attachments as links. These contents are similar in all courses with the same style. The students do not have the chance to change e-course style because there is one style only that designed for the course.

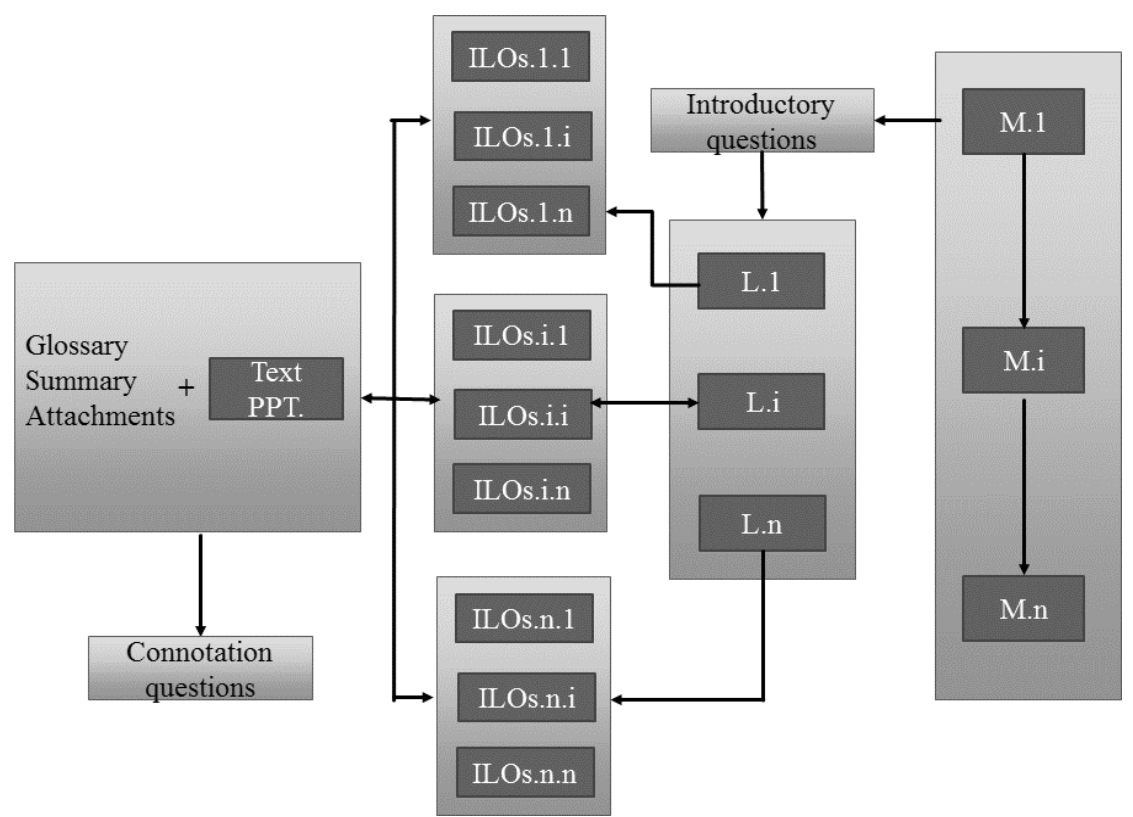

Fig. 1. Traditional e-learning course process.

As soon as students finished the lesson, they could answer the five questions that are the same question that found before the lesson in the introductory questions section. After the completion of the five questions, the ILOs of the lesson should be achieved. This traditional e-learning system does not match the needs of students and there is gap between the students desired and conceptual base of the implementation of e-learning

\section{Proposed Framework}

The enhancement process in e-learning system that is used through CC for e-course, the system is divided into layers as services, as Software as a Service (SaaS) layer in CC is the most abstract layer of the cloud service layers which enables users to run hosted applications on the cloud and use them remotely. SaaS provides an accessing to the required applications through the internet on demand. In the SaaS layer, the (Cloud Service Providers) CSP provides a single instance on the cloud for multiple users. In the proposed framework, SaaS contains course styles and questions services. Students can sign in these layers through 
the profile and can use the preferred style which is built in profile. In the time being of effectively implement the cloud computing in higher education Helwan Cloud in our case. The enhanced educational process is positively running as a result of the effective adoption of cloud computing in higher education; especially in the field of e-learning course process; as shown in Fig. 2.

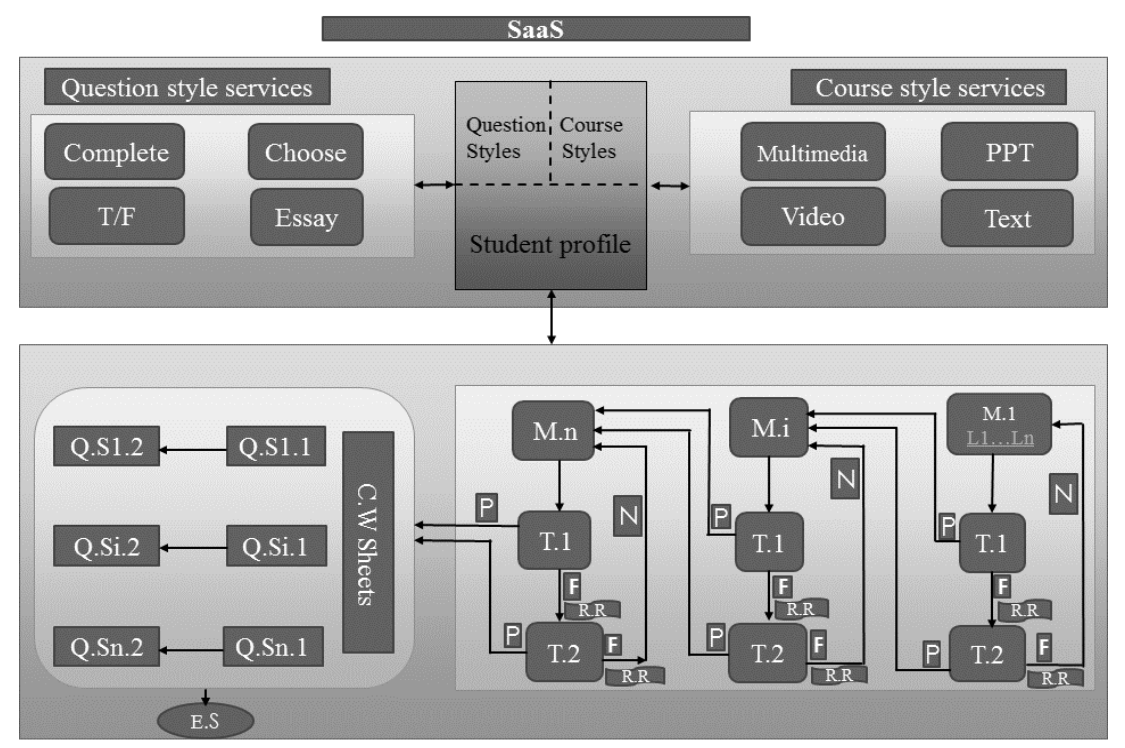

Fig. 2. Enhancement process framework in e-learning course.

This paper focuses in the enhancement process in the e-learning course through two points of views: first, the e-courses have been enhanced by offering different learning styles for course as along with achieving the Intended Learning Outcomes (ILOs) of course and its lessons. Second, the enhanced model of the e-course process is taking into consideration the satisfaction of students, the enhancement in the learning process, and system performance. The following discussion will present the enhanced educational process in higher education especially in the field of e-course process. The enhanced e-learning course process in higher education based on cloud computing is a good indicator to make learning system being generalized. The enhanced e-learning courses need to be activated by the all effective ways depend on how the students will be satisfied by using the enhanced e-course process.

The enhanced process based on cloud computing serve the students' needed and requests as a tailor. The enhanced process presents all styles of the course as well as the whole different styles of questions as services that belongs and achieves the different ILOs of lessons. The enhanced process of e-learning field is presented as follows:

1) The course is divided into different modules, each module has many lessons that have its related ILOs that achieved the aim and objective of learning and teaching lesson. The different learning styles of lessons forms depend on the student's profile.

2) Student's profile has the preferred style of course and questions style. The student should pass the first test of the lesson, then turning the second module. In the case of student failure, the system will generate a report review to the student and give permission for the student to repeat the test, as a second chance, to be passed to operate the second module. In the case of student failure for the second time, the system offers and repeats lesson with a new different style of teaching and learning style based on the report review that has presented to the student. The new style is chosen randomly.

3) As soon as, students finish and pass the whole modules' tests, students are ready for answering the different course work sheets of instructors to get the course degree. Students have the opportunities to 
solve two different exams for each module. The two exams were prepared to be a good assessment to the students to answer the course work sheet with their preferred style depends on their profile on the system. Considering that students finish the course work sheets, students directly get their degrees. These degrees were calculated by the evaluation strategy that is based on instructors' vision (e.g. min, max, average and/or any other suitable evaluation strategy).

To conclude the e-learning course of the educational process is effectively enhanced depending on technology such cloud computing in the educational process. The cloud allows different styles of the lesson that are not found in the traditional way. Cloud computing solves the problem of storage, hardware special configuration, special software application, and building new infrastructures.

\section{Case Study: Findings Analysis and Discussions}

In this section, we demonstrate the analysis results in measuring the quality of educational process after fully adapted by CC to enhance e-course in the learning process for higher education. Data has been collected to declare the success pilot to claim that the proposed model is a valuable contribution to the field of e-course enhancement in the learning process. The study distributed a questionnaire to different segments before and after applying the new proposed system. Table 1 shows the sample size and number of respondents for each of two different groups in the research case.

Table 1. Sample Size and Number of Respondents

\begin{tabular}{lll}
\hline \hline \multicolumn{1}{c}{ Groups } & Sample & Responses \\
\hline Faculty of Business Information System (BIS) & 752 & 631 \\
Faculty of Computers and Information (FCI) & 180 & 161 \\
Faculty of Business administration and Commerce & 1580 & 1440 \\
\hline \hline
\end{tabular}

A survey that included nine questions for measuring the students' satisfaction is conducted. Focusing on the results of the survey, we found that $\mathrm{p}$-value $=0.0$ which explores the full awareness of the students of the technology. There was a variance of Mean scores findings towards an increase after applying the proposed system which indicates that there are more satisfaction after the full implementation of the proposed system. Other measures have been performed such as the Coefficient of Variation (CV = (Standard deviation (SD) / Mean)*100). The results showed that the proposed system overcome the problems and obstacles of students and especially technical problems that be found in the traditional system.

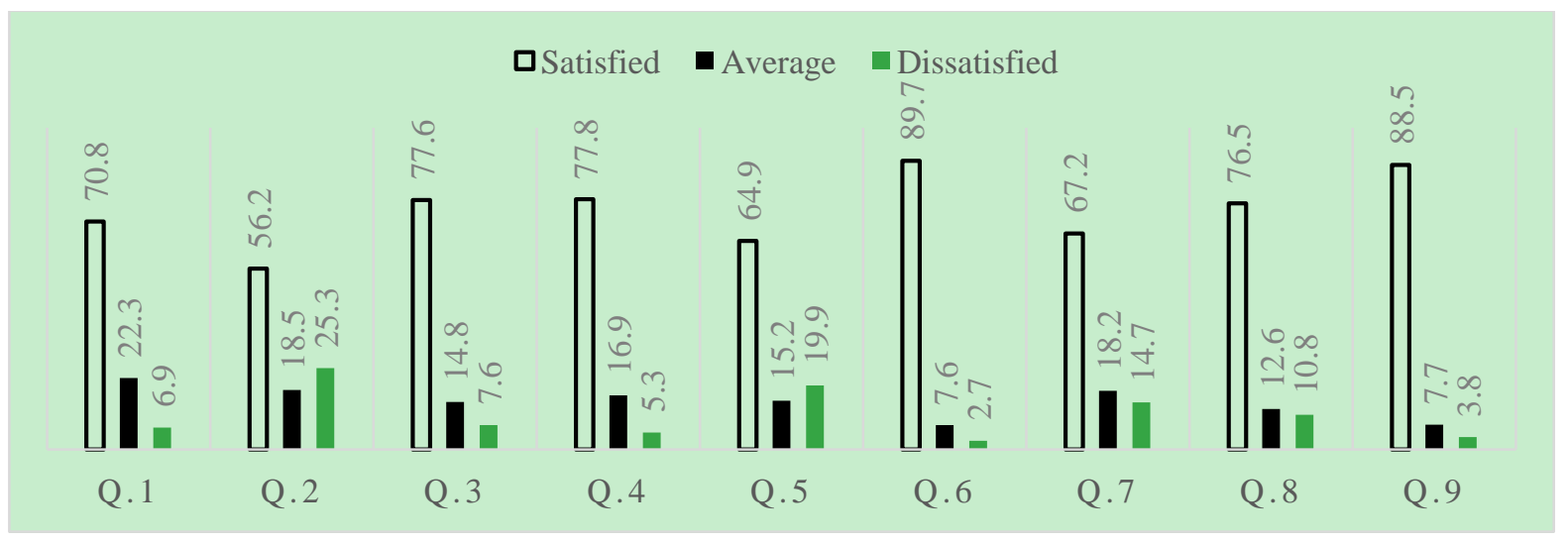

Fig. 3. Students' satisfaction of the overall enhancement in e-learning course process.

Fig. 3 presents the students' satisfaction percentage for the proposed adaptive e-course in the learning process on the previously selected segments. We can clearly find a visible increase in the level of the students' satisfaction ratio. This ratio is a good indicator of how Helwan University has a great step forward 
in solving one of its critical problems as a direct business impact resulting from the introduction of the new technology in the university.

Increasing the university customer satisfaction was one of the main strategic and complex objectives. To achieve this objective, Helwan University gave much attention and investment to the new technology. However, the university students' satisfaction linkage is not that simple. Consequently, in order to gain such direct positive impact from the adoption of the new technology, Helwan University promoted, and still does, students satisfaction which is likely to lead to higher student profitability.

As for the criteria of measuring the system performance based on five different major criteria; the following figures and tables shows the results of the applied measurements:

Fig. $4 \mathrm{a}$ and Fig. $4 \mathrm{~b}$ present the comparison findings of measuring the performance test between the proposed enhanced e-course in the adapted e-learning system in Helwan and traditional e-learning system for the average response time. The curves and lines indicate that the average response times of the proposed adapted e-course system is less than the average response time in traditional e-learning one.

The comparison findings of measuring the performance test between adapted e-course system throughput and the traditional system throughput pointed that the adapted e-course system is more effective than traditional throughput as shown in Fig. 5a and Fig. 5b. The adapted e-course system can service a huge volume of students' requests in a tiny response time. The throughput measures indicate that the throughput for adapted e-course is more sufficient in educational process than the site of traditional system throughput.

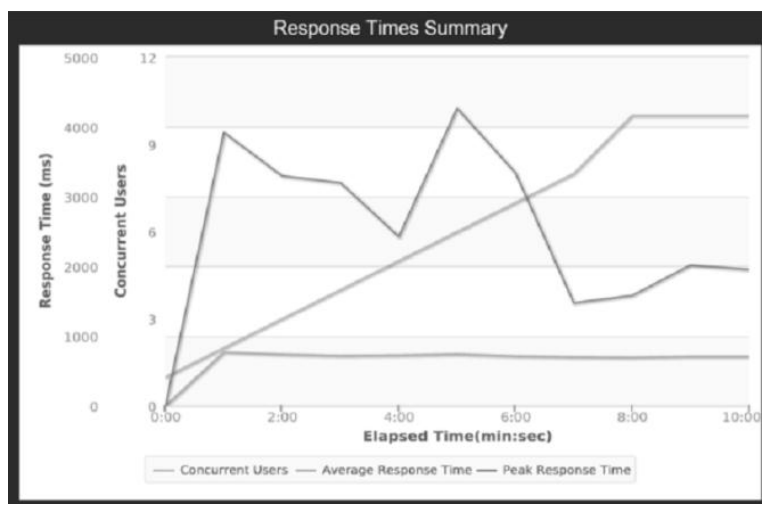

Fig. 4a. Response time of new proposed system.

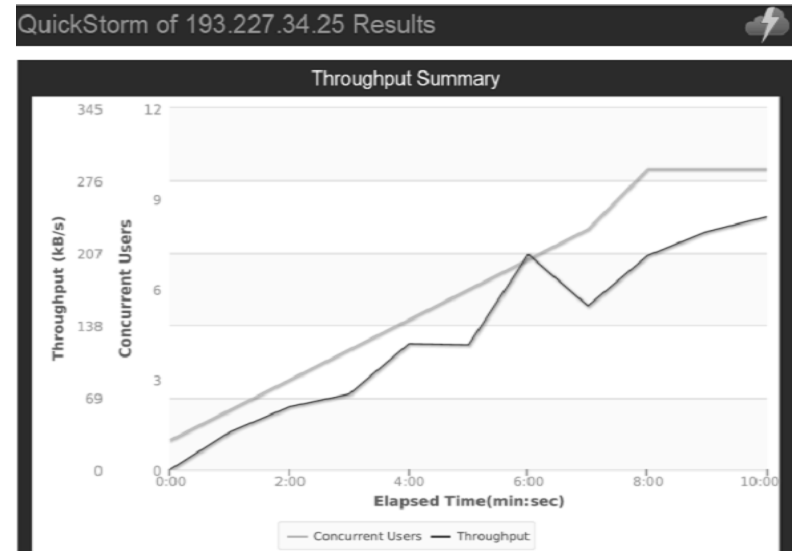

Fig. 5a. Proposed system throughput summary.

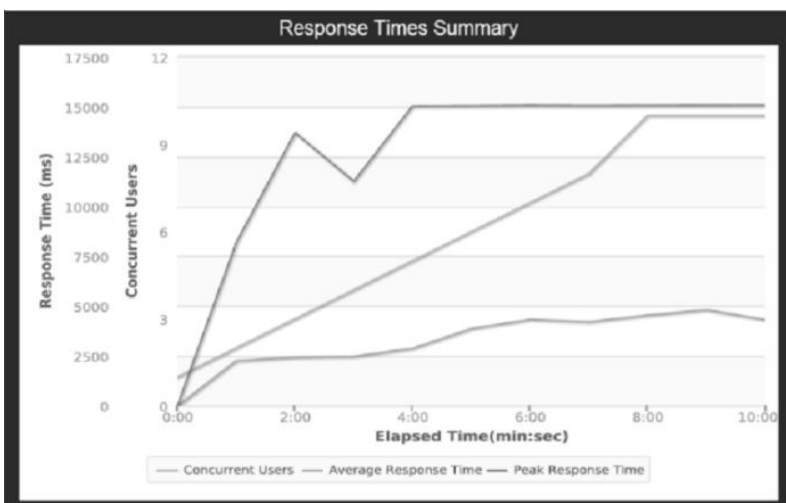

Fig. 4b. Response time of traditional system.

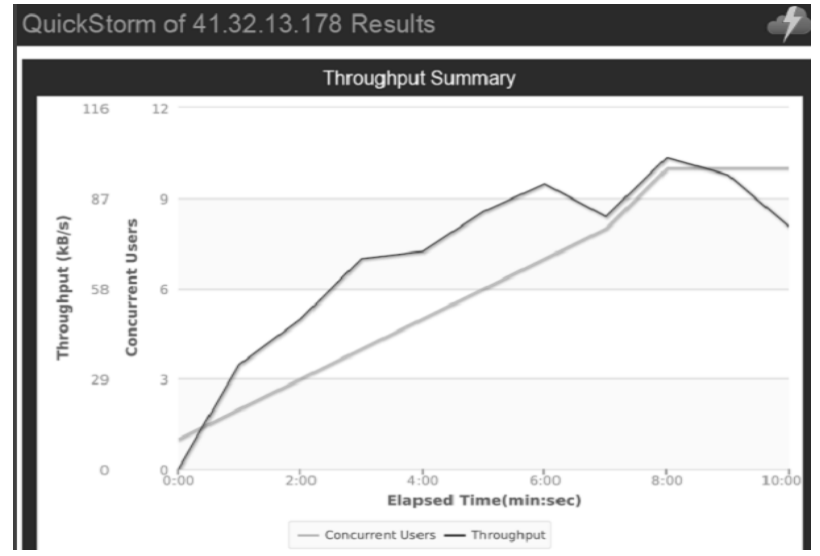

Fig. 5b. Traditional system throughput summary.

Fig. 6a and Fig. 6b show the error in adapted e-course system (is zero \%) comparing with the error of the traditional system (is $92 \%$ ). This indicates the success of adapted e-course based on cloud computing for 
enhancing the course process with no error.

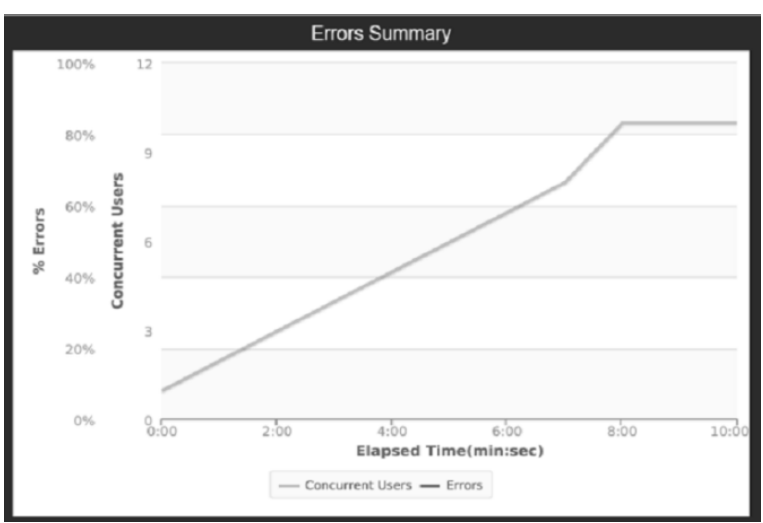

Fig. 6a. Proposed system errors summary.

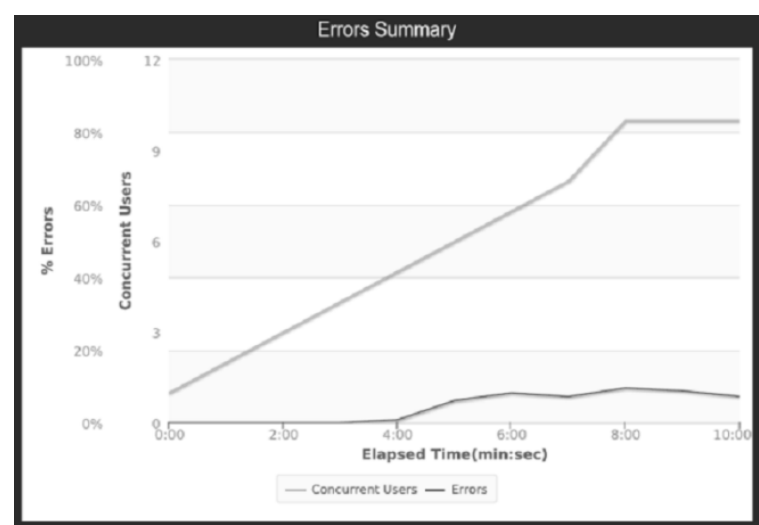

Fig. 6b. Traditional system errors summary.

Fig. 7a and Fig. 7b present the comparison curves and lines for the average response time, peak response time and errors summary of the two systems. These curves and lines indicate that adapted e-course system based on cloud is more powerful and sufficient for enhancing the learning process in higher education than traditional e-learning system.

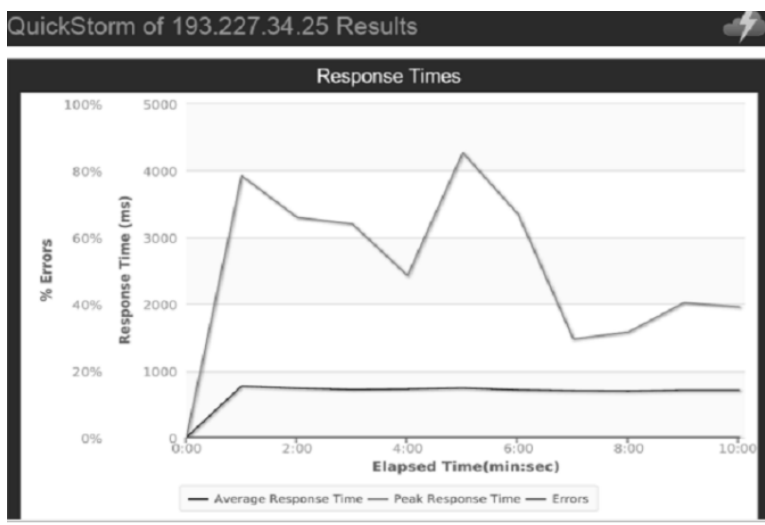

Fig. 7a. Proposed system average response time, peak response time and errors.

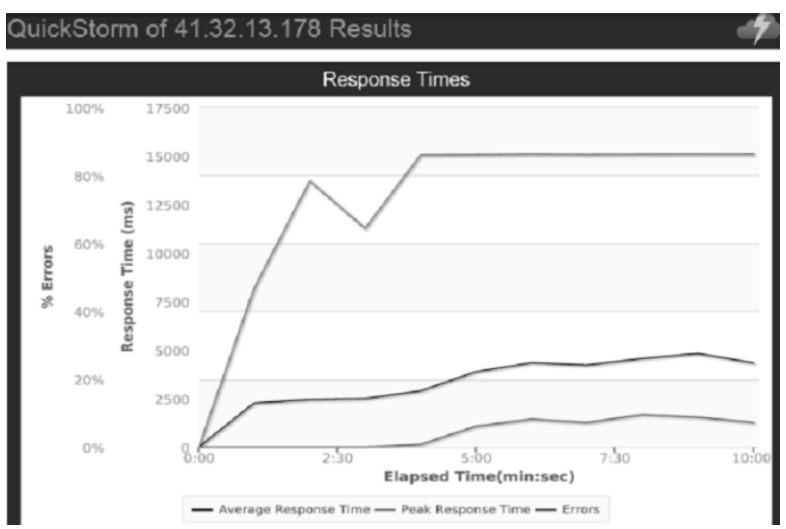

Fig. 7b. Traditional System Average response time, peak response time and errors.

Table 2 presents the comparison for the average students' results for Information Systems course. These results indicate that adapted e-course system based on cloud is more powerful and sufficient than traditional e-learning system for enhancing the learning process and raising the students' learning level in higher education especially in the field of e-learning course process.

Table 2. Comparison for the Average Students' Results

\begin{tabular}{|c|c|c|c|c|c|c|c|c|c|c|c|}
\hline \multirow[t]{2}{*}{ Academic Year } & \multicolumn{2}{|c|}{ Excellent } & \multicolumn{2}{|c|}{ Very Good } & \multicolumn{2}{|c|}{ Good } & \multicolumn{2}{|l|}{ Fair } & \multicolumn{2}{|l|}{ Fail } & \multirow{2}{*}{$\begin{array}{l}\text { Total } \\
\text { Attendance }\end{array}$} \\
\hline & No & $\%$ & No & $\%$ & No & $\%$ & No & $\%$ & No & $\%$ & \\
\hline Traditional system & 210 & 15 & 253 & 18 & 491 & 35 & 168 & 12 & 280 & 20 & 1402 \\
\hline $\begin{array}{l}\text { adapted e-course } \\
\text { system }\end{array}$ & 535 & 38.2 & 313 & 22.3 & 371 & 26.5 & 160 & 11.4 & 23 & 1.6 & 1402 \\
\hline
\end{tabular}

\section{Conclusion and Future Work}

This study ultimately leads to a fuller comprehension of the relationship between the implementing of cloud computing technology and its impact on the enhancement of the education process in an environment 
such as Egypt. The proposed system has proved that there is an effective impact of CC adoption on e-learning strategy in Egyptian universities. The comparison of the traditional e-learning system supported by existing e-learning site and the enhanced e-learning system by Helwan cloud presents the tremendous advantages of the proposed system and how it is effectively enhanced the e-learning educational process especially in the field of e-learning course process.

We suggest that future research should be carried out to explore other factors that can affect the relationship between the process of adopting cloud computing and enhancing other educational processes. Further research also needs to investigate differences between the private and public education institutions in terms of the effective adoption process itself (e.g. procedures and stages) in Egypt.

\section{Acknowledgment}

With deep appreciation, the authors would like to thank Eng. Shrouk Hoassam for her support to this publication.

\section{References}

[1] Al-Zoube, M., (June 2009). E-Learning on the cloud. The International Arab Journal of e-Technology, Princess Sumaya University for Technology, Jordan, 1(2), 58-64.

[2] Bora, U., \& Ahmed, M. (January 2013). E-Learning using cloud computing. International Journal of Science and Modern Engineering (IJISME), 1(2), 9-13.

[3] Kwan, R., Fox, R., Chan, F., \& Tsang, P. (2008). Enhancing Learning through Technology: Research on Emerging Technologies and Pedagogies.

[4] Richard, N. (2008). The tower and the cloud: Higher education in the age of cloud computing. EDUCAUSE, USA.

[5] Zeng, W., Zhao, Y., Ou, K., \& Song, W. (2009). Research on cloud storage architecture and key technologies. Proceedings of the 2nd International Conference on Interaction Sciences: Information Technology, Culture and Human, ACM, NY, USA.

[6] Madan, D., Pant, A., Kumar, S., \& Arora, A. (February 2012). E-learning based on cloud computing, International Journal of Advanced Research in Computer Science and Software Engineering, 2(2).

[7] Nasr, M., \& Ouf, S. (2012). A proposed smart e-learning system using cloud computing services: PAAS, IAAS and Web 3.0, IJET, Helwan University, Cairo, Egypt, 7(3), 19-24.

[8] Horvath, W. J., \& Bruner, J. S. (1960). The Process of Education, Cambridge: Harvard University Press, 56-57.

[9] Burke, P. J., \& Dunn, S. (2006). Communicating Science: Exploring reflexive pedagogical approaches, Teaching in Higher Education, 11(2), 219-232.

[10] Bora, U., \& Ahmed, M. (January 2013). E-Learning using cloud computing. International Journal of Science and Modern Engineering, 1(2).

[11] Madan, D., Pant, A., Kumar, S., \& Arora, A. (February 2012). E-learning based on cloud computing. International Journal of Advanced Research in Computer Science and Software Engineering, 2(2).

[12] Nguyen, T. D., Nguyen, D. T., \& Cao, T. H. (2014). Acceptance and use of information system: e-Learning based on cloud computing in vietnam, Proceedings of ICT-EurAsia.

[13] Madhumathi, C., \& Gopinath, G. (November 2013). An Academic cloud framework for adapting e-learning in universities. International Journal of Advanced Research in Computer and Communication Engineering, 2(11), 4480-4484.

[14] Masud, A. H., \& Huang, X. (2012). An e-learning system architecture based on cloud computing. World Academy of Science, Engineering and Technology, 6. 
[15] Abu El-Ala, N. S., Awad, W. A., \& El-Bakry, H. M. (2012). Cloud computing for solving e-learning problems. International Journal of Advanced Computer Science and Applications, 3(12).

[16] Alshwaier, A., Youssef, A., \& Emam, A. (January 2012). A new trend for e-learning in KSA using educational cloud. Advanced Computing: An International Journal, 3(1), 81-97.

[17] Nasr, M., \& Ouf, S. (2011). An ecosystem in e-learning using cloud computing as platform and Web2.0, The Research Bulletin of Jordan, II(IV).

[18] Ebrahim, G. A. (December 2012). Budget-aware e-learning systems on cloud computing environments: A genetic approach. International Journal of Information and Education Technology, 2(6).

[19] El-Sofany, H. F., Al Tayeb, A., Alghatani, K., \& El-Seoud, S. A. (January 2013). The Impact of cloud computing technologies in e-learning, ICL2012, 8(1).

[20] El-Seoud, M. S., El-Sofany, H. F, Islam A. T., Taj-Eddin, F., Nosseir, A., \& El-Khouly, M. M. (2013). Implementation of web-based education in Egypt through cloud computing technologies and its effect on higher education. Higher Education Studies, 3(3).

[21] Khedr, A. E., Kholeif, S. A., \& Hessen, S. H. (April 2015). Enhanced cloud computing framework to improve the educational process in higher education: A case study of Helwan University in Egypt. Council for Innovative Research, International Journal of Computers \& Technology, 14(6), 5814- 5823.

[22] Khedr, A. E., Kholeif, S. A., \& Hessen, S. H. (March 2015). Adoption of cloud computing framework in higher education to enhance educational process. International Journal of Innovative Research in Computer Science and Technology, 3(3), 150-156.

[23] Mircea, M., \& Andreescu, A. (2011). Using cloud computing in higher education: A strategy to improve agility in the current financial crisis, IBIMA. From http://www.ibimapublishing.com

[24] Al-Zoube, M. (June 2009). E-Learning on the cloud. The International Arab Journal of e-Technology, Princess Sumaya University for Technology, Jordan, 1(2), 58-64.

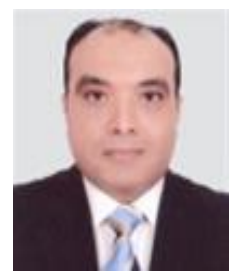

Ayman E. Khedr is an Associate Professor, now he is the head of Information Systems Department, Faculty of Computers and Information Technology, Future University in Egypt. Also, he is the supervisor of the Quality Assurance Department and a member of continuing education board. He has worked at the Faculty of Computers and Information, Helwan University in Egypt, and he has been the general manager of Helwan E-Learning Center. His research is concentrated around the themes (scientific) data and model management, data mining, bioinformatics and cloud computing.

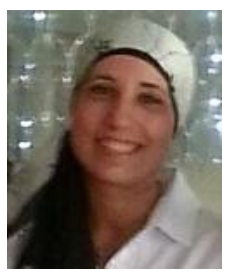

Amira M. Idrees is an Associate Professor in the Faculty of Computers and Information, Fayoum University.

Her research interests include knowledge discovery, text mining, opinion mining, sentimental analysis, cloud computing, software engineering, and data warehousing. 